\title{
Intraarticular corticosteroid injection in adhesive capsulitis: are two doses better than a single dose? a randomized prospective study
}

\author{
Ramanagouda Biradar, Santosh S. Nandi, Amit Patel*, Arravind Pillai
}

Department of Orthopaedics, Shri. B. M. Patil Medical College, Vijaypur, BLDE University, Karnataka, India

Received: 21 July 2016

Accepted: 11 August 2016

\author{
*Correspondence: \\ Dr. Amit Patel, \\ E-mail: amitpatel3219@gmail.com
}

Copyright: () the author(s), publisher and licensee Medip Academy. This is an open-access article distributed under the terms of the Creative Commons Attribution Non-Commercial License, which permits unrestricted non-commercial use, distribution, and reproduction in any medium, provided the original work is properly cited.

\begin{abstract}
Background: The present study aimed to compare the effectiveness of a single dose and two doses of intraarticular corticosteroids injections followed by home exercise programme in patients with adhesive capsulitis.

Methods: The study was done over two years. Eighty four patients with adhesive capsulitis were enrolled in the study. The patients were randomly assigned to two groups: In group I 38 patients were given a single dose of intraarticular corticosteroid injection $(1 \mathrm{~mL}, 40 \mathrm{mg}$ methylprednisolone acetate) followed by a twelve-week home exercise programme. In group II 46 patients were given two doses of intraarticular corticosteroid injection $(1 \mathrm{~mL}, 40$ $\mathrm{mg}$ methylprednisolone acetate) at first and third week followed by home exercise programme. All the patients were assed for functional out come at six and twelve weeks using Shoulder pain and disability index (SPADI) and Constant Moore's shoulder score (CMS).

Results: Both groups showed considerable improvement from the baseline, but no significant differences were found between the two groups at twelve weeks. Mean changes in range of motion and shoulder pain and disability indexpain score were statistically no different between the two groups at the twelve weeks.

Conclusions: Intraarticular corticosteroids have the additive effect of providing rapid pain relief when combined with home exercise program in adhesive capsulitis. No significant differences in outcome were found in patients treated with a single or two doses of corticosteroid injection.
\end{abstract}

Keywords: Adhesive capsulitis, Randomised clinical trials, Review, Corticosteroids injections

\section{INTRODUCTION}

Adhesive capsulitis is a common cause of shoulder pain and disability and is characterized by shoulder pain and gradual loss of active and passive shoulder motion. It affects $2-5 \%$ of the general population. ${ }^{1}$

The aetiology of adhesive capsulitis remains unclear. It has been associated with older age, diabetes, female gender, post trauma, prolonged immobility, cervical spondylosis, thyroid disease, stroke, myocardial infarcts and presence of autoimmune disease. ${ }^{2}$ Three phases have been described in the progression of the condition: increasing pain and stiffness, in the first two -nine months, a steady-state period from four to twenty months, and a spontaneous recovery lasting between five and twenty six months. ${ }^{3}$ Some authors believe it is a selflimiting disorder, but others suggest a chronic disorder leading to longer term disability. In the recovery stage, approximately $7-15 \%$ of patients permanently lose their full range of motion. Exercises, physiotherapy programmes including ultrasound, laser, transcutaneous electrical stimulation and iontophoresis, oral nonsteroidal anti-inflammatory drugs, oral steroid and intraarticular injections or their combinations are used to treat adhesive capsulitis. In resistant patients manipulation or surgical release by arthroscopic adhesivolysis or hydrodilatation has been advised. ${ }^{4}$ Multiple studies have showed merits and demerits of different treatment options for adhesive capsulitis. ${ }^{5-9}$ 
Some studies show minimal improvement with a single corticosterioid injection and physiotherapy. We undertook this study to assess whether a second dose of intraarticular corticosteroid has a benefit over a single dose when combined with a home exercise programme in cases of adhesive capsulitis.

\section{METHODS}

This prospective study was conducted at Department of Orthopaedics, Shri B. M. Patil Medical College, Vijaypur from May 2013-December 2015. The study included all newly diagnosed patients of adhesive capsulits. A diagnosis of adhesive capsulitis was made when there was a presence of shoulder pain with limitation of both active and passive movements of the glenohumeral joint of $25 \%$ in at least two directions. ${ }^{10}$

\section{Inclusion criteria}

Patients aged between 30-70 years who were diagnosed with adhesive capsulitis, persistence of symptoms between six weeks and six months, patients with restriction in abduction to less than 120 degrees and patients with $50 \%$ reduction in external rotation as compared with the contralateral side were included in the study.

\section{Exclusion criteria}

Patients with previous shoulder surgery, history of steroid injections in the same shoulder, other suspected shoulder pathology (tumour, rotator cuff rupture. infection, arthritis), bleeding diathesis, cervical spine pathology, history of trauma to the shoulder, pregnancy were excluded from the study.

A total of eighty four patients with adhesive capsulitis were enrolled in this study. Informed consent was obtained from all patients. All patients were randomized after initial evaluation by selecting a sealed unmarked envelope containing a letter that informed them of their group. Group I patients $(n=38)$ with fourty two shoulder involvements were given intraarticular injection of $1 \mathrm{~mL}$, $40 \mathrm{mg}$ methylprednisolone acetate followed by a twelveweek home exercise programme. Group II patients $(\mathrm{n}=$ 46) with fifty eight shoulder involvements were given two doses of intraarticular injection of $1 \mathrm{~mL}, 40 \mathrm{mg}$ methylprednisolone acetate at time of presentation and third week with home exercise programme. Initial evaluation included the recording of demographic data, medical history, and relevant comorbidities.

The injections were given using a posterior approach, with the patient seated, and the affected arm rotated internally. The site of injection was marked by placing the index finger of the on the coracoid process and the thumb on the angle between the spine of the scapula and the acromion. The needle was introduced $1 \mathrm{~cm}$ below the thumb and aimed at the coracoid process.
A $2 \mathrm{ml}$ syringe, fitted with a $5 \mathrm{~cm}, 21$ gauge needle was used. All the injections were given by a single surgeon. The second injections were given using the same technique. Following the injection patients were advised to do a home exercise programme. Initially, pendulum exercises and passive shoulder self-stretching in forward elevation, external rotation, horizontal adduction and internal rotation were advised. Patients were instructed to stretch the shoulder to the point of tolerable discomfort two times a day. The goal was to stretch the capsule sufficiently to allow restoration of normal shoulder biomechanics.

All patients were assessed at six and twelve weeks following the injection. At the follow up, passive range of motion of the involved shoulder was measured in all planes with a long-arm goniometer with patients in supine position. All movements of the shoulder were assessed and recorded. Visual analogue scale (VAS) was used to assess night pain. Shoulder pain and disability index (SPADI) was administered to all patients to evaluate shoulder disability, and was evaluated with SPADI- pain, SPADI-disability and SPADI- total. The five-item pain subscale addresses pain experienced during activities of daily living, and were graded from no pain to worst pain imaginable. The eight disability items addressed the level of difficulty in performing activities of daily living. These items were graded from no difficulty to so difficult it required help. Subscales were scored in a three-part process. First, item scores within the subscale were summed. Then, this sum was divided by the summed distance possible across all items of the subscale to which the person responded. Third, this ratio was multiplied by 100 to obtain a percentage. Higher scores on the subscale indicate greater pain and greater disability. To obtain the shoulder pain and disability index total score, pain and disability subscales were averaged. $^{11,12}$

Data were shown as mean \pm standard deviation or median (interquartile range), where appropriate. Categorical variables were presented as percentages. Medians were compared using the Mann-Whitney U test. Differences among repeated corticosteroid injection in adhesive capsulitis measures were evaluated by Friedman TwoWay ANOVA by ranks. When the P-value from the Friedman test statistics was statistically significant, multiple comparison tests were used to determine pairwise differences between groups. At the sixth and twelfth weeks, actual changes in levels according to baseline were calculated. Between-group comparisons for actual changes were evaluated by Mann-Whitney U test. For categorical comparisons, chi-square or Fisher's exact test were used, where appropriate. $\mathrm{P}$ value less than 0.01 was considered statistically significant.

\section{RESULTS}

In our study eighty four patients were selected and randomly assigned to two groups. In group I, (38 
patients) $39.5 \%$ were males and $60.5 \%$ were females. In group II, (46 patients) both males and females constituted $50 \%$ as given in Table 1 . Mean age in group I was 62.9 years and group II was 59.6 years as shown in Table 2. Patients were assessed using SPADI Score and ConstantMurley scoring (CMS).

Table1: Gender distribution of patients among groups.

\begin{tabular}{|lllll|}
\multirow{2}{*}{ Gender } & \multicolumn{2}{c}{ Group 1 } & \multicolumn{2}{c|}{ Group 2 } \\
& N & Percent & N & Percent \\
\hline Male & 15 & 39.5 & 23 & 50 \\
\hline Female & 23 & 60.5 & 23 & 50 \\
\hline Total & 38 & 100 & 46 & 100 \\
\hline
\end{tabular}

Table 2: Age distribution of patients among groups.

\begin{tabular}{|lllll|}
\hline & N & Min. & Max. & Mean \pm SD \\
\hline Group 1 & 38 & 50 & 80 & $62.9 \pm 7.1$ \\
\hline Group 2 & 46 & 44 & 80 & $59.6 \pm 7.6$ \\
\hline
\end{tabular}

Baseline SPADI score at presentation for group I was $11.6 \pm 0.9$ and group II was $11.6 \pm 0.8$ ( $\mathrm{p}>0.05)$. SPADI score at 6 weeks was $9.6 \pm 0.6$ for group I and $7.8 \pm 1.2$ for group II, (p <0.01) which showed significant improvement. At 12 weeks SPADI score further improved to $4.7 \pm 1.1$ for group I and $4.4 \pm 0.7$ for group II $(\mathrm{p}>0.05)$ as given in Table 3.

Table 3: Mean SPADI score of patients among groups.

\begin{tabular}{|llll|}
\hline \multicolumn{4}{|c|}{ SPADI score $(\mathrm{Mean} \pm \mathrm{SD})$} \\
& Group 1 & Group 2 & p value \\
\hline Baseline & $11.6 \pm 0.9$ & $11.6 \pm 0.8$ & $>0.05$ \\
\hline Week 6 & $9.6 \pm 0.6$ & $7.8 \pm 1.2$ & $<0.01^{*}$ \\
\hline Week 12 & $4.7 \pm 1.1$ & $4.4 \pm 0.7$ & $>0.05$ \\
\hline
\end{tabular}

Both groups showed significant improvement in SPADI score from the baseline at 12 weeks with no significant difference between the two groups. Total improvement of SPADI score from baseline to 12 weeks for group I was $59.5 \%$ ( $\mathrm{p}<0.01$; significant) and for group II was $62.1 \%$ (p <0.01; significant). Group II showed considerable improvement over group I at 6 weeks. There was no significant difference between two groups at 12 weeks as in Table 4.

Table 4: Percentage improvement in mean SPADI score from baseline.

\begin{tabular}{|c|c|c|c|c|c|c|}
\hline & \multicolumn{6}{|c|}{ Mean SPADI Score } \\
\hline & Group 1 & \% improvement & p value & Group 2 & \% improvement & p value \\
\hline Baseline & $11.6 \pm 0.9$ & - & - & $11.6 \pm 0.8$ & - & - \\
\hline Week 6 & $9.6 \pm 0.6$ & 17.3 & $<0.01 *$ & $7.8 \pm 1.2$ & 32.8 & $<0.01 *$ \\
\hline Week 12 & $4.6 \pm 1.1$ & 59.5 & $<0.01 *$ & $4.4 \pm 0.7$ & 62.1 & $<0.01 *$ \\
\hline
\end{tabular}

Findings for CM score were similar to that of the SPADI score. Baseline CM score for group I was $24.6 \pm 1.8$ and group II was $25.1 \pm 2.2$ ( $\mathrm{p}>0.05$ ). At 6 weeks CM score improved to $10.9 \pm 0.9$ for group I and $8.3 \pm 1.6$ for group II (p <0.01; significant). At 12 weeks CM score further improved to $4.7 \pm 1.1$ for group I $4.4 \pm 0.7$ for group II (p $>0.05$ ) as given in Table 5. At 6 weeks, group II showed considerable improvement over group I $(55.8 \%$ for group $\mathrm{I} ; \mathrm{p}<0.01$ and $66.9 \%$ for group II; $\mathrm{p}<0.01)$. Both groups showed significant improvement in $\mathrm{CM}$ score from the baseline at 12 weeks ( $64.8 \%$ for group I; $p<0.01$ and
$67.7 \%$; $\mathrm{p}<0.01$ for group II). There was no significant difference between the two groups at 12 weeks as in Table 6.

Table 5: Mean CM score of patients among groups.

\begin{tabular}{|llll|}
\hline \multicolumn{5}{|c|}{ Mean CM score } \\
& Group 1 & Group 2 & p value \\
\hline Baseline & $24.6 \pm 1.8$ & $25.1 \pm 2.2$ & $>0.05$ \\
\hline Week 6 & $10.9 \pm 0.9$ & $8.3 \pm 1.6$ & $<0.01^{*}$ \\
\hline Week 12 & $8.7 \pm 1.6$ & $8.1 \pm 0.9$ & $>0.05$ \\
\hline
\end{tabular}

Table 6: Percentage improvement in mean CM score from baseline.

\begin{tabular}{|c|c|c|c|c|c|c|}
\hline & \multicolumn{6}{|c|}{ Mean CM score } \\
\hline & Group 1 & \% improvement & p value & Group 2 & \% improvement & p value \\
\hline Baseline & $24.6 \pm 1.8$ & & & $25.1 \pm 2.2$ & & \\
\hline Week 6 & $10.9 \pm 0.9$ & 55.8 & $<0.01 *$ & $8.3 \pm 1.6$ & 66.9 & $<0.01 *$ \\
\hline Week 12 & $8.7 \pm 1.6$ & 64.8 & $<0.01 *$ & $8.1 \pm 0.9$ & 67.7 & $<0.01 *$ \\
\hline
\end{tabular}

\section{DISCUSSION}

In this study we aimed to compare the outcome of single and two steroid injections in patients with adhesive capsulitis when combined with a home exercise therapy.
Neviaser introduced the term 'adhesive capsulitis' in 1945 and described the inflammatory process. ${ }^{13}$ Cytokines have been implicated recently in the inflammation and fibrosis described in adhesive capsulitis. Cytokines are involved in the initiation and 
termination of repair processes in musculoskeletal tissues, and their sustained production has been shown to result in tissue fibrosis. ${ }^{14}$ Early treatment with intraarticular corticosteroid may provide a chemical ablation of synovitis, thus limiting the subsequent development of fibrosis and shortening the natural history of the disease. Steroid injection therapy has been advised in adhesive capsulitis based on the belief that inflammation plays an important role in the pathogenesis.

Studies have shown contradictory findings with intraarticular corticosteroid therapy. In a study by Rizk et al, he compared four treatments for adhesive capsulitis and found that patients who were administered steroid with lidocaine had the advantage of partial transient pain relief. $^{15}$ In a study by Bulgen et al, he randomized patients to treatment with steroid, physical therapy, ice and benign neglect. The initial response to treatment was most marked in patients treated with steroid; however, no significant difference in final long-term outcome was reported when treatment groups were compared. ${ }^{16}$

Ryans et al. found that patients having intraarticular corticosteroid therapy had better outcome in disability scores but not in pain and range of motion in the six week, but all the therapy groups had improved to a similar degree with respect to all outcome measures at sixteen weeks. ${ }^{17}$ One trial of fluoroscopically guided injection with and without physiotherapy found corticosteroid-injected patients had less disability and better range of motion outcome at six weeks compared with physical therapy alone or placebo injection. ${ }^{17}$

Van Der Windt et al. compared the effectiveness of corticosteroid injection with physiotherapy for the treatment of the painful stiff shoulder and concluded that the differences between those who received injections and those treated with physiotherapy resulted mainly from comparatively fast relief of symptoms that occurs after injections. ${ }^{18}$ Similar to the results of our study, all these studies indicated that corticosteroid injection is more effective in the improvement of adhesive capsulitis in the early follow-up period; however, this difference disappears in the late follow-up period. Other papers evaluating the effectiveness of steroid or exercise or physical therapy found no difference in all stages in pain, disability and range of motion between the groups. They all advised corticosteroid injection as being less costly to administer. Green et al reviewed randomized clinical trials of efficacy of non-steroidal anti-inflammatory drugs, intraarticular and subacromial corticosteroid injection, oral corticosteroid, physiotherapy, manipulation under anaesthesia, hydrodilatation and surgery in patients with shoulder pain, and reported that there was little evidence to support or refute the use of any of the common interventions. 6,7

When we assessed the systematic review of randomized clinical trials of the effectiveness of corticosteroid injections for shoulder pain, we found that intraarticular corticosteroid injection for adhesive capsulitis may be beneficial, although its effect may be small and not wellmaintained; there were inconsistent short-term results and limited evidence for the long-term outcome.

Exercise therapy is critically important in adhesive capsulitis. Patients should be educated well about the exercise programme and recovery process. Stretching should be the focus of the treatment. It can be taken beyond the limits of the available range of motion. Strengthening of the scapula musculature and rotator cuff muscles can be added to increase strength and endurance. A $90 \%$ improvement can be achieved using only four directional stretching exercises. In this study, we administered a home exercise programme to patients in both the groups. Patients who received two doses of intraarticular corticosteroid showed more improvement at the twelve week.

In this study SPADI and CMS were used to assess the effectiveness of treatment of adhesive capsulitis. The combination of the corticosteroid injection and therapeutic exercises was equally effective when compared with the therapeutic exercises alone at the end of twelve weeks.

\section{CONCLUSION}

Intraarticular corticosteroids have the additive effect of providing rapid pain relief when combined with home exercise program adhesive capsulitis. In patients with adhesive capsulitis who have pain symptom predominantly, intraarticular corticosteroid therapy could be advised concomitantly with exercise.

Funding: No funding sources

Conflict of interest: None declared

Ethical approval: The study was approved by the institutional ethics committee

\section{REFERENCES}

1. Wolf JM, Green A. Influence of comorbidity onself assessment instrument scores of patients with idiopathic adhesive capsulitis. J Bone Joint Surg Am. 2002;84:1167-72.

2. Hannafin JA, Chiaia TA. Adhesive capsulitis. Clin Orthop. 2000;372:95-109.

3. Gam AN, Schydlowsky P, Rossel I, Remvig L, Jensen EM. Treatment of 'frozen shoulder' with distension and glucorticoid compared with glucorticoid alone. Scand J Rheumatol. 1998;27:425-30.

4. Dias R, Cutts S, Massoud S. Frozen shoulder. BMJ. 2005;331:1453-6.

5. Van der Heijden GJ, Van der Windt DA, De Winter AF. Physiotherapy for patients with soft tissue shoulder disorders: a systematic review of randomised clinical trials. BMJ. 1997;315:25-30. 
6. Green S, Buchbinder R, Glazier R, Forbes A. Systematic review of randomised controlled trials of interventions for painful shoulder: selection criteria, outcome assessment, and efficacy. BMJ. 1998;316:354-60.

7. Green S, Buchbinder R, Glazier R, Forbes A. Interventions for shoulder pain. Cochrane Database Syst Rev. 2000;2:CD001156.

8. Green S, Buchbinder R, Glazier R, Forbes A. Withdrawn: Interventions for shoulder pain. Cochrane Database Syst Rev. 2007;3:CD001156.

9. Buchbinder R, Green S, Youd JM. Corticosteroid injections for shoulder pain. Cochrane Database Syst Rev. 2003;1:CD004016.

10. Van der Windt DA, Bouter LM. Physiotherapy or corticosteroid injection for shoulder pain? Ann Rheum Dis. 2003;62:385-7.

11. Carette S, Moffet H, Tardif J, Bessette L, Morin F, Frémont $\mathrm{P}$, et al. Intraarticular corticosteroids, supervised physiotherapy, or a combination of the two in the treatment of adhesive capsulitis of the shoulder. Arthritis Rheum. 2003;48(3):829-38.

12. Roach KE, Budiman-Mak E, Norvarat $\mathrm{S}$, Lertratanakul Y. Development of a Shoulder Pain and Disability Index. Arthritis Care Res. 1991;4:143-9.

13. Neviaser JS. Adhesive capsulitis of the shoulder. A study of the pathological findings in periarthritis of the shoulder. J Bone Joint Surg. 1945;27:211-22.
14. Border WA, Noble NA. Transforming growth factor beta in tissue fibrosis. $\mathrm{N}$ Engl $\mathrm{J}$ Med. 1994;331:1286-92.

15. Rizk TE, Pinals RS, Talaiver AS. Corticosteroid injection in adhesive capsulitis: investigation of their value and site. Arch Phys Med Rehabil. 1991;72:20-2.

16. Bulgen DY, Binder A, Hazelman BL, Dutton J, Roberts S. Frozen shoulder: Prospective clinical study with an evaluation of three treatment regimens. Ann Rheum Dis. 1984;43:353-60.

17. Ryans I, Montgomery A, Galway R, Kernohan WG, Mckane R. A randomized Corticosteroid injection in adhesive capsulitis controlled trial of intraarticular triamcinolone and/or physiotherapy in shoulder. Rheumatology. 2005;44:529-35.

18. Van der Windt DA, Koes BW, Deville W, Boeke AJP, De Jong BA, Bouter LM. Effectiveness of corticosteroid injections versus physiotherapy for treatment of painful stiff shoulder in primary care: randomised trial. BMJ. 1998;317:1293-6.

Cite this article as: Biradar R, Nandi SS, Patel A, Pillai A. Intraarticular corticosteroid injection in adhesive capsulitis: are two doses better than a single dose? a randomized prospective study. Int J Res Orthop 2016;2:159-63. 